\title{
Effectiveness of Preradiosurgical Embolization with NBCA for Arteriovenous Malformations - Retrospective Outcome Analysis in a Japanese Registry of 73 Patients (J-REAL study)
}

\author{
Shigeru Miyachi, MD, PhD', Takashi Izumi, MD, PhD², Tetsu Satow, MD, PhD², \\ Kittipong Srivatanakul, MD, MSc ${ }^{4}$, Yasushi Matsumoto, $\mathbf{M D}^{5}$, Tomoaki Terada, MD, $\mathrm{PhD}^{6}$, \\ Yuji Matsumaru, MD, $\mathrm{PhD}^{7}$, Hiro Kiyosue, MD, $\mathrm{PhD}^{8}$, J-REAL study investigators
}

Purpose: Recent reports have posed doubts about the effect of preradiosurgical embolization in brain arteriovenous malformation (AVM) because it makes the planning of stereotactic radiosurgery (SRS) difficult and has the risk of recanalization out of the target. We investigated whether the performance and quality of embolization may influence the success of SRS based on a retrospective case cohort study.

Materials and Methods: Seventy-three patients who underwent embolization followed by SRS between 2003 and 2012 in eight institutes with neurointerventionists were considered. They were divided into the following two groups at 3 years of follow up after the final SRS: "successful occlusion group" (S group), with radiologically complete occlusion of AVM; and "non-successful occlusion group" (N group) with persistent remnant nidus or abnormal vascular networks. Patient background, AVM profile, embolization performance grade and complications were compared in each group. The quality of embolization was evaluated with the new grading system: embolization performance grade (E grade), specializing the achievement of nidus embolization. E grade A was defined as sufficient nidus embolization with more than half of the total number of feeders achieving nidus penetration. E grade B was defined as less than half achievement of nidus embolization,

${ }^{1}$ Neuroendovascular Therapy Center, Aichi Medical University, Nagakute, Japan

2Department of Neurosurgery and Endovascular Neurosurgery, Nagoya University Graduate School of Medicine, Nagoya, Japan

${ }^{3}$ Department of Neurosurgery, National Cerebral and Cardiovascular Center, Suita, Japan

${ }^{4}$ Department of Neurosurgery, Tokai University Hospital, Isehara, Japan

${ }^{5}$ Department of Neuroendovascular Therapy, Kohnan Hospital, Sendai, Japan

${ }^{6}$ Department of Neurosurgery, Showa University Fujigaoka Hospital, Yokohama, Japan

'Department of Neurosurgery, University of Tsukuba Hospital, Tsukuba, Japan

${ }^{8}$ Department of Radiology, Oita University Hospital, Oita, Japan

Received: July 20, 2017; Revised: August 2, 2017; Accepted: August 10, 2017

Correspondence to: Shigeru Miyachi, MD, PhD, Department of Neurosurgery and Neuroendovascular Therapy, Aichi Medical University, 1-1 Yazakokarimata, Nagakute, 480-1195 Aichi, Japan.

Tel. +81-561-62-3311 Fax.+81-561-63-2879 E-mail: miyachi.shigeru.752@mail.aichi-med-u.ac.jp

This is an Open Access article distributed under the terms of the Creative Commons Attribution Non-Commercial License (http://creativecommons.org/licenses/by-nc/3.0) which permits unrestricted non-commercial use, distribution, and reproduction in any medium, provided the original work is properly cited. 
and $\mathrm{E}$ grade $\mathrm{C}$ was defines as failure to perform nidus embolization.

Results: Forty-three patients were included in the S group, and 29 patients were included in the $\mathrm{N}$ group. The size and Spetzler-Martin grade of AVM and the rate of diffuse type was higher in the $\mathrm{N}$ group without statistical significance. The embolization performance level according to $\mathrm{E}$ grade indicated a significantly higher rate of successful embolization with more than $50 \%$ of nidus penetration in the $\mathrm{S}$ group $(\mathrm{P}<0.001)$. This difference was also confirmed in the subanalysis for limited cases, excluding smaller AVMs with complete occlusion with $S R S$ alone $(P=0.001)$.

Conclusion: The cause of the unsuccessful result of post-embolization SRS might be the large, diffuse angioarchitecture, but proper embolization with a high rate of nidus penetration to avoid recanalization is more important. Effective embolization is essential to contribute to and promote the effect of radiosurgery.

Key Words : Arteriovenous malformation; Nidus; Embolization; Radiosurgery; Quality

Preradiosurgical embolization of cerebral arteriovenous malformations (AVMs) has been warranted as a significant treatment to eliminate the risk of hemorrhage during the latency period after radiosurgical treatment, and to achieve AVM volume reduction to a size amenable to radiosurgical treatment, resulting in earlier obstruction $[1,2]$. The treatment of inappropriate factors, such as flow-related aneurysms, is warranted because proximal and pedicular aneurysms and intranidal aneurysms have a $7 \%$ to $10 \%$ annual risk of hemorrhage $[3,4]$.

However, embolization has recently been criticized as a useless option for radiosurgery because embolization decreases the obliteration rates after stereotactic radiosurgery (SRS) compared with radiosurgical treatment alone [5]. Recanalization of embolized feeder after RS is seen in 5-7\% of patients, and some reports question the efficacy of embolization [6-14]. The recanalization or vascular remodeling of remaining feeders tends to occur in cases with incomplete nidus embolization and far proximal feeder occlusion $[15,16]$. For this reason, radiosurgeons may struggle to plan the interested area because the part with pretended obstruction after embolization with a risk of late recanalization is outside the target. By contrast, proper nidus embolization will prevent recanalization $[2,7]$ and can contribute to achieving a preferable result from SRS.

In Japan, where there are a large number of Gamma Knife centers, the treatment option with SRS following embolization has a comparatively higher rate among the combined therapeutic modalities [17], and this difference affects the rate of favorable results. This multicenter study, J-REAL (Japanese registry of
Radiosurgery following Embolization for Arteriovenous maLformations), is a retrospective analysis of the selected AVM cases treated with SRS following embolization that was planned to clarify the efficacy of embolization and address the discrepancy in the results between Japan and western countries.

\section{MATERIALS AND METHODS}

\section{Outline of the study}

A retrospective review of AVMs treated between 2003 and 2012 with embolization followed by SRS was performed. The data were harvested from institutes, enrolling experienced neurointerventionists who had proper and secure strategies for the endovascular treatment of AVM. The clinical materials were AVMs with a maximum diameter of more than $1 \mathrm{~cm}$ in patients older than 6 years of age. Patients who underwent SRS or direct surgery before embolization, except for emergency ventricular drainage, were excluded. All AVMs were embolized with NBCA mixture in one or staged sessions, and no cases with Onyx embolization were included. The SRS tool was a Gamma Knife in all cases. Patients treated with other methods, such as LINAC and X knife, were excluded. The timing of SRS was specified as within 6 months after the final embolization, and the decision of the marginal dose and targeting area was based on the guidelines of each Gamma Knife center. The operators of endovascular treatment were senior board experts trained by the Japanese society of neuroendovascular therapy with experience in more than 20 cases of AVM embolization. Similarly, the operators of the Gamma Knife were required to have experience with more than 
50 radiosurgery cases for AVM.

The performance of endovascular treatment was impartially judged by multiple neurointerventionists, and the final image judgment was performed by the experienced multiple radiosurgeons 3 years after the final radiosurgery. This study was approved of the local institutional review board.

\section{Clinical data}

We investigated patent profile including gender, age, clinical manifestation, undergone initial treatment and general complications, and AVM profile including location, Spetzler-Martin grade[18], maximum diameter; volume, modified radiosurgery-based arteriovenous malformation score (mRBAS)[19] and angioarchitecture including nidus type $\$$, daughter nidus, draining pattern, varix, associated aneurysm, and meningeal feeders. AVM volumes were calculated from a 3-dimensional angiogram after determination of the radius ( $\mathrm{r}$ ) on three orthogonal planes using the formula for an ellipsoid $(4 \pi \mathrm{r} 1 \times \mathrm{r} 2 \times \mathrm{r} 3 / 3)$. mRBAS were determined by the following equation: $\mathrm{AVM}$ score $=$ $\left(0.1 \times\right.$ volume in $\left.\mathrm{cm}^{3}\right)+(0.02 \times$ age in years $)+(0.5 \times$ location). The location values are as follows: frontal/temporal/parietal/occipital/intraventricular/corp us callosum/cerebellar $=0$, and basal ganglia/ thalamus/brainstem $=1$. Nidus type was categorized into compact type and diffuse type. Compact type was defined as AVM with clearly demarcated nidus without daughter ones. While, diffuse type was defined as AVM with abnormal vessel dilatation or a non-shunting abnormal vascular network surrounding the nidus, particularly expressed at the watershed area between different perfusion territories.

\section{Performance of the treatment}

\section{A. Performance of embolization}

Data were collected for the total number of accessible / inaccessible feeders, successful / incomplete occlusion of fistulous feeders, and successful / unsuccessful nidus penetration as proximal feeder occlusion alone. The achievement level of embolization was defined in the newly provided categorization, embolization performance grade (E-grade), to exclude the operator's subjective preference (Table 1). E grade A was defined as sufficient nidus embolization with more than $50 \%$ of total number of feeders achieving nidus penetration. E grade $\mathrm{B}$ was defined as less than $50 \%$ achievement of nidus embolization, and $\mathrm{E}$ grade $\mathrm{C}$ was defines as failure to perform nidus embolization due to a lack of access, technical error or fistulous AVM with no nidus components. Grades A and B were subdivided according to the components and treatment of fistulous feeders. The final embolization rate was calculated as the result of the three-dimensional volume reduction of the nidus. The size of the remaining nidus after embolization was expressed as the maximum diameter of the residual nidus. Procedure-related or perioperative complications associated with embolization and the neurological deterioration due to the complications were registered.

\section{B. Performance of radiosurgery}

The effect of SRS was evaluated at 2 years after the first operation. The post-SRS radiological evaluation was performed using the original grading system (SRSgrade). Patients with complete occlusion of AVM in the final angiogram were classified as SRS grade A. Patients who had a fine abnormal vascular network without AV shunt remaining in the site of the nidus were classified as SRS grade B, and those with a remaining nidus with obvious $\mathrm{AV}$ shunt were classified

Table 1. Classification of the Grade of Embolization Performance (E Grade)

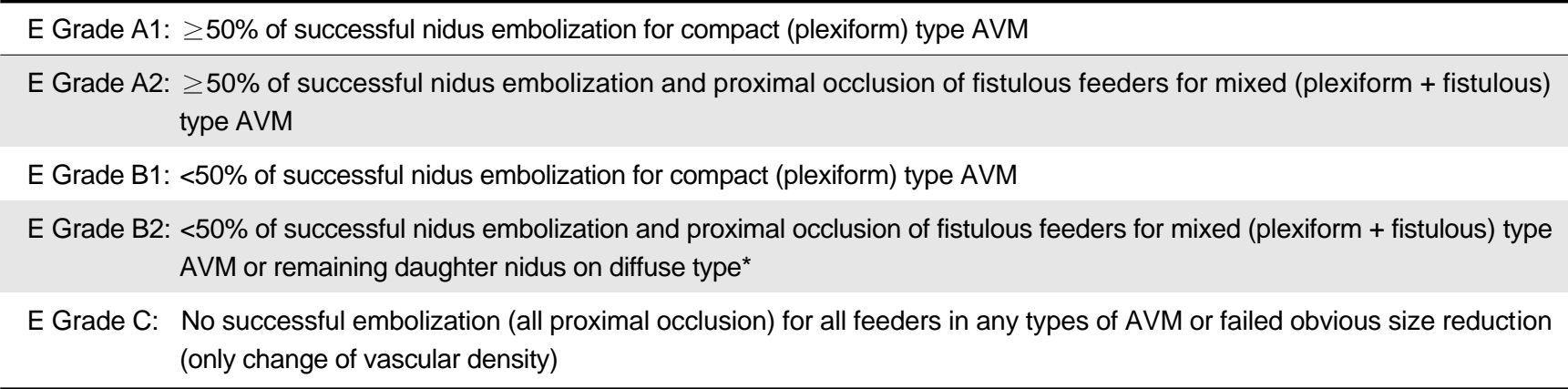

*: Including remnant daughter nidus on diffuse type 


\section{Effectivenss of Preradiosurgical Embolization of Brain AVM}

as SRS grade C. Other information concerning the radiosurgery, including the duration between embolization and SRS; major adverse events after the radiosurgery, such as rupture or delayed complications; and the final clinical outcome were registered.

\section{Statistical analysis}

Patients with SRS grade A were categorized as the "successful occlusion group" (S group), and the patients in SRS grades B and C were categorized as the "non-successful occlusion group" (N group). These two groups were compared in terms of patient background, AVM profile and embolization performance. As a sub-analysis, SRS grade-B patients were independently studied to determine differences from SRS grade-C patients. The statistical analysis of categorical variables was performed using the $\boldsymbol{x}^{2}$ and Fisher exact tests. The comparison of means was performed using Student's t-test, and an analysis of variance (ANOVA) followed by Bonferroni post hoc testing was performed, as appropriate. Predictive factors in the univariate analysis concerning size and embolization specification were entered into a multivariate logistic regression analysis using a stepwise method. The percentage of incidence and 95\% confidence intervals (CI) were calculated for all considered variables and results. P-values $<0.05$ were considered to indicate significance.

\section{RESULTS}

\section{Patient profile}

A total of 73 patients met the inclusion criteria and underwent embolization followed by SRS during the study period (Table 2 ). There were 40 males and 33 females ranging from 6-78 years old with a mean age of 35.8 years. Of the 30 unruptured AVMs, the clinical manifestations were asymptomatic in 10 , convulsion in 10 , headache in five, and focal neurological deficits including cognitive and psychological function deficits in five. Of 43 patients with ruptured AVMs, 20 patients had intracerebral hemorrhage, 16 had intraventricular hemorrhage, and seven had subarachnoid hemorrhage. The initial treatments before embolization were medication for seizure, intracranial pressure control, and vital stabilization in 23 patients, as well as ventricular drainage in four patients. Precedent general complications were recognized in 4 patients and neurological deficits before treatment were observed in 18 patients, including mild deficits ( $\mathrm{mRS} 1$ ) in 9 patients, middle (mRS 2$)$ in 3 patients and severe ( $\mathrm{mRS}$
4) in 6 patients.

\section{AVM profile}

The AVM profile is summarized in Table 3. Of the AVMs, the location was frontal in 20, temporal in 8 , parietal in 10, occipital in 11, cerebellum in 16, thalamostriate in three and brain stem in four. Large AVMs extending over multiple areas were sorted according to the area containing of the largest part. For the SpetzlerMartin grade, there were nine AVMs in grade 1, 17 in grade 2, 32 in grade 4 and one in grade 5 . The preoperative mean maximum diameter was $31.6 \mathrm{~mm}$ (range 11-72 $\mathrm{mm}$ ) and the mean volume was $13.8 \mathrm{ml}$ (range 1-46 ml). The distribution of the volume was less than $5 \mathrm{ml}$ in 24 AVMs, $6-10 \mathrm{ml}$ in 15 AVMs, $11-20 \mathrm{ml}$ in 13 AVMs, $21-30 \mathrm{ml}$ in 10 AVMs, 31-40 $\mathrm{ml}$ in 9 AVMs and more than $40 \mathrm{ml}$ in 2 AVMs. The median mRBAS before embolization was 2.13, and the distribution of AVMs in mRBASs was as follows: $\leq 1.00$ in $14,1.01-$ 1.50 in $11,1.51-2.00$ in 16 and $>2.00$ in 31 .

Regarding the angioarchitecture of the AVMs, 52 were classified as compacted types and 21 were classified as diffuse types; a daughter nidus was observed in five AVMs. The draining pattern of the AVMs was as follows: single superficial drainage in 18 , single deep drainage in 11, multiple superficial drainage in 32 and multiple deep drainage in 12 . The cases with both superficial and deep drainers were classified to the category of the main drainage side. Varices on the drainers were observed in six AVMs. Associated aneurysms were found in 22 AVMs, including 13 proximal feeder aneurysms, 3 flow-related aneurysms and 6 intranidal aneurysms. Of these, 12 aneurysms were treated with embolization in addition to the embolization for AVM. Seventeen AVMs were also supplied by meningeal feeders, and 9 of these were embolized in a manner similar to that use for AVMs supplied by pial feeders.

\section{Performance of embolization}

According to our embolization grading system, the AVMs were distributed in grades as follows: 12 in EGrade A1, 20 in E-Grade A2, 19 in E-Grade B1, 18 in E-Grade B2 and two in E-Grade C (Table 4). The mean final volume reduction rate was $61.2 \%$. The maximum diameter of the remaining nidus was almost zero in 7 AVMs, $<1 \mathrm{~cm}$ in 22 AVMs, $1-2 \mathrm{~cm}$ in 24 AVMs, 2-3 $\mathrm{cm}$ in 13 AVMs, and $\geq 3 \mathrm{~cm}$ in 7 AVMs. Perioperative complications occurred in 14 patients, including perioperative or delayed hemorrhage in eight patients, postoperative convulsion in two patients, and other 


\section{Shigeru Miyachi, et al.}

minor complications in four patients. Of these, two patients had neurological deterioration with score changes of $\geq 2$ on the modified Rankin Scale.

\section{Performance of radiosurgery}

The AVMs classified by SRS grade as follows: 44 in SRS-grade A, 18 in SRS-Grade B and 11 in SRSGrade $C$ (Table 4). The median duration between final embolization and SRS was 1.9 months. Delayed adverse events occurred in 4 patients, including hemorrhage in three patients and cyst formation in one patient. Of these, two patients presented with neurological deterioration and a score change of $\geq 2$ on the modified Rankin Scale.

\section{Comparison of profiles by SRS grade}

The data of patients and AVM profiles were compared between the $\mathrm{S}$ and $\mathrm{N}$ groups (Tables 2 and $3)$. For patient profiles, there was no difference between the two groups in terms of age distribution, clinical manifestation, and initial treatment methods. While the dominancy of gender is different between $\mathrm{S}$ group (female: 16/44 (36\%)) and $\mathrm{N}$ group (17/29 $(59 \%))$ with female dominancy, in particular significantly different between $\mathrm{S}$ group and SRS grade $\mathrm{C}$ $(9 / 11(82 \%))$ with female dominancy $(\mathrm{P}=0.015)$.

For the clinical manifestation, initial treatments and preceding neurological deficits, there were no significant differences between the two groups. The AVM location and Spetzler-Martin Grade showed no deviation and had a similar distribution in both groups. The sizes of the AVMs also had a similar distribution. However, the mean maximum diameter (SRS-grade A: $28.7 \mathrm{~mm}, \mathrm{~B}: 32.9 \mathrm{~mm}, \mathrm{C}: 40.7 \mathrm{~mm}$ ) showed no signifi-

Table 2. Patient Profile

\begin{tabular}{|c|c|c|c|c|c|c|c|}
\hline \multirow{2}{*}{\multicolumn{2}{|c|}{$\begin{array}{l}\text { Grade of radiosurgical effect (SRS grade) } \\
\text { category of group } \\
\text { total number }\end{array}$}} & \multirow{2}{*}{\multicolumn{2}{|c|}{$\begin{array}{c}\text { A } \\
\text { S group } \\
44\end{array}$}} & \multirow{2}{*}{$\begin{array}{l}\text { B } \\
18\end{array}$} & \multirow{2}{*}{\multicolumn{2}{|c|}{$\begin{array}{l}B+C \\
N \text { group } \\
29\end{array}$}} & \multirow[b]{2}{*}{$\mathrm{S}$ vs $\mathrm{N}$ group } \\
\hline & & & & & & & \\
\hline \multicolumn{8}{|l|}{ Patient profile } \\
\hline Gender (M:F) & & 40 vs. 33 & 28 vs. 16 & 10 vs. 8 & 2 vs. 9 & 12 vs. 17 & NS \\
\hline Mean age (ranc & & $38.3(6 \sim 78)$ & $38.5(6 \sim 78)$ & $30.9(10-58)$ & $33.2(13-62)$ & $31.8(10 \sim 62)$ & NS \\
\hline Clinical & Unruptured & & & & & & NS \\
\hline \multirow[t]{8}{*}{ Manifestation } & No symptom & 10 & 6 & 2 & 2 & 4 & \\
\hline & Convulsion & 10 & 4 & 4 & 2 & 6 & \\
\hline & Headache & 5 & 4 & 1 & 0 & 1 & \\
\hline & Focal neurological symptoms & 5 & 2 & 1 & 2 & 3 & \\
\hline & Ruptured & & & & & & NS \\
\hline & Intracerebral hemorrhage & 20 & 14 & 4 & 2 & 6 & \\
\hline & Intraventricualr hemorrhage & 16 & 9 & 4 & 3 & 7 & \\
\hline & Subarachnoid hemorrhage & 7 & 5 & 2 & 0 & 2 & \\
\hline \multirow[t]{5}{*}{ Initial treatment } & & & & & & & NS \\
\hline & No treatment & 42 & 25 & 9 & 8 & 17 & \\
\hline & Medical treatment & 23 & 15 & 7 & 1 & 8 & \\
\hline & Ventricular drainage & 4 & 2 & 2 & 0 & 2 & \\
\hline & Others & 4 & 2 & 0 & 2 & 2 & \\
\hline \multicolumn{2}{|c|}{ Precedent neurological deficits } & & & & & & NS \\
\hline & None (mRS 0) & 55 & 32 & 13 & 10 & 23 & \\
\hline & Mild (mRS 1) & 9 & 5 & 3 & 1 & 4 & \\
\hline & Medium (mRS 2, 3) & 3 & 2 & 1 & 0 & 1 & \\
\hline & Severe $(m R S \geq 4)$ & 6 & 5 & 1 & 0 & 1 & \\
\hline
\end{tabular}


Effectivenss of Preradiosurgical Embolization of Brain AVM

Table 3. AVM Profile

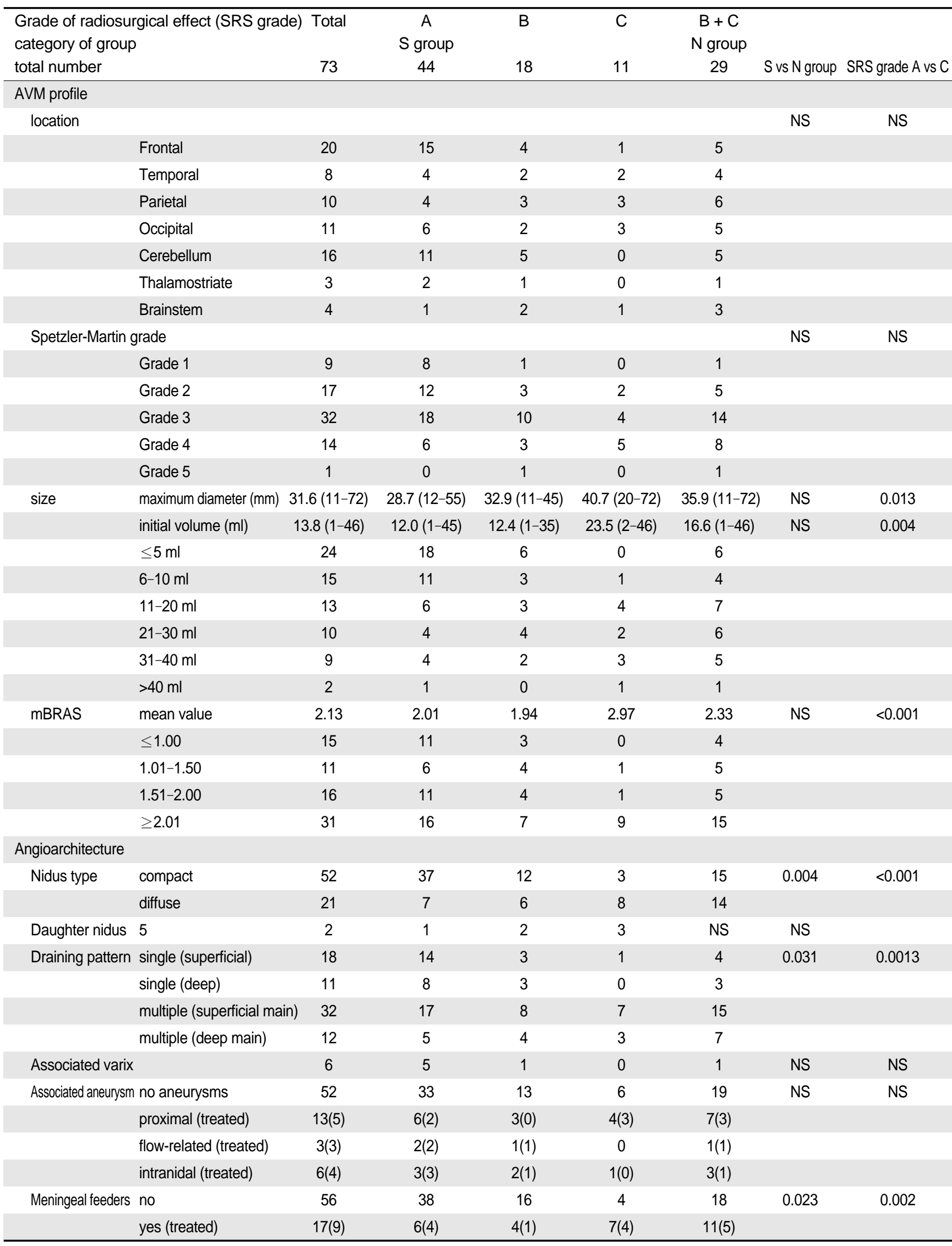

mBRAS: modified radiosurgery-based arteriovenous malformation (AVM) score 
cant difference between the SRS-grade A and B groups, but they were significantly larger in the SRSgrade $\mathrm{C}$ group than group $\mathrm{A}(\mathrm{P}=0.013)$. The mean initial volume (SRS-grade A: $12.0 \mathrm{ml}, \mathrm{B}: 12.4 \mathrm{ml}, \mathrm{C}$ : $23.5 \mathrm{ml}$ ) showed similar tendency and significant difference between Grade A and $\mathrm{C}$ groups $(\mathrm{P}=0.004)$. The mean mRBAS (SRS-grade A: 2.01, B: 1.94, C: 2.97) was also significantly higher in SRS-Grade $C$ AVMs $(\mathrm{P}<0.001)$

Regarding angioarchitecture, a diffuse type of nidus was significantly more frequent in the $\mathrm{N}$ group (14/29 (48\%), $\mathrm{P}=0.004)$, particularly in Grade C AVMs (8/11 $(73 \%), \mathrm{P}<0.001)$, than the $\mathrm{S}$ group $(7 / 44(16 \%))$. Multiple drainers were significantly more frequent in the $\mathrm{N}$ group $(22 / 29(76 \%))$ than the $\mathrm{S}$ group $(22 / 44$ $(50 \%)(\mathrm{P}=0.031)$. The presence of a daughter nidus, associated aneurysm and varix were not different among the groups. The supply from the meningeal feeder (S group: 6/44 (14\%), N group:11/29 (38\%) ) was significantly frequent in the $\mathrm{N}$ group $(\mathrm{P}=0.023)$.

\section{Comparison of embolization performance by SRS grade}

Table 4 shows the comparison of embolization performance by SRS grade. The E grade groups were divided into two groups by the rate of successful nidus embolization; one was the successful embolization group, including E grades A1 and A2 ( $=32)$; and the other was the unsuccessful group, including E grades $B 1, B 2$ and $C(n=41)$. In the former group, SRS grade A was achieved in 30 patients $(94 \%)$, while in the latter, SRS grade A was achieved in only 14 patients (34\%). There was a significant difference between the two groups $(\mathrm{P}<0.001)$. Because a small AVM has more potential for complete occlusion after SRS without the aid of embolization, subanalysis was performed to target the relatively larger AVMs ( $n=43$; S group: 21 (49\%), N group: 22 (51\%)), excluding AVMs less than

Table 4. Performance of Embolization

\begin{tabular}{|c|c|c|c|c|c|c|c|}
\hline \multirow{2}{*}{\multicolumn{2}{|c|}{$\begin{array}{l}\text { Grade of radiosurgical effect (SRS grade) } \\
\text { category of group } \\
\text { total number }\end{array}$}} & \multicolumn{3}{|c|}{ S group } & \multicolumn{3}{|c|}{$\begin{array}{l}\mathrm{B}+\mathrm{C} \\
\mathrm{N} \text { group }\end{array}$} \\
\hline & & 73 & 44 & 18 & 11 & 29 & S vs N group \\
\hline \multicolumn{8}{|l|}{ Performance of embolization } \\
\hline \multirow[t]{5}{*}{ Embolization grade } & $E$ grade $A 1$ & 12 & 12 & 0 & 0 & 0 & $<0.001$ \\
\hline & E grade $A 2$ & 20 & 18 & 2 & 0 & 2 & \\
\hline & $\mathrm{E}$ grade $\mathrm{B} 1$ & 19 & 8 & 7 & 4 & 13 & \\
\hline & E grade $B 2$ & 18 & 6 & 5 & 7 & 12 & \\
\hline & E grade $\mathrm{C}$ & 2 & 0 & 2 & 0 & 2 & \\
\hline Final embolization rate & & $61.2 \%$ & $63.6 \%$ & $60.0 \%$ & $53.6 \%$ & $57.6 \%$ & NS \\
\hline Final results of embolization & complete occlusion & 7 & 6 & 1 & 0 & 1 & NS \\
\hline Size of remained nidus (diameter) & $<1 \mathrm{~cm}$ & 22 & 16 & 5 & 1 & 6 & \\
\hline \multirow[t]{2}{*}{$1-2 \mathrm{~cm}$} & 24 & 14 & 8 & 2 & 10 & & \\
\hline & $2-3 \mathrm{~cm}$ & 13 & 3 & 4 & 6 & 10 & \\
\hline$\geq 3 \mathrm{~cm}$ & 7 & 5 & 0 & 2 & 2 & & \\
\hline \multirow[t]{4}{*}{ Procedure-related complications } & total & 14 & 7 & 5 & 2 & 7 & NS \\
\hline & hemorrhage (inta- \& perioperative) & e) 8 & 6 & 2 & 0 & 2 & \\
\hline & convulsion & 2 & 0 & 1 & 1 & 2 & \\
\hline & others & 4 & 1 & 2 & 1 & 3 & \\
\hline \multirow[t]{4}{*}{ Influence of complication on outcome } & none & 11 & 7 & 2 & 2 & 4 & NS \\
\hline & mRS 1 rank down & 1 & 0 & 1 & 0 & 1 & \\
\hline & mRS 2 rank down & 1 & 0 & 1 & 0 & 1 & \\
\hline & mRS 3 rank down & 1 & 0 & 0 & 1 & 1 & \\
\hline
\end{tabular}


Table 5. Performance of Radiosurgery

\begin{tabular}{|c|c|c|c|c|c|c|c|}
\hline \multirow{2}{*}{$\begin{array}{l}\text { grade of radiosurgical effect (SRS grade) } \\
\text { category of group } \\
\text { total number }\end{array}$} & & \multicolumn{3}{|c|}{ S group } & \multicolumn{2}{|c|}{$\mathrm{N}$ group } & \\
\hline & & 73 & 44 & 18 & 11 & 29 & S vs $N$ group \\
\hline \multicolumn{8}{|l|}{ Performance of radiosurgery } \\
\hline \multirow[t]{3}{*}{ Post-radiosurgery complications } & total & 4 & 0 & 1 & 3 & 4 & 0.022 \\
\hline & hemorrhage, rebleeding & 3 & 0 & 1 & 2 & 3 & \\
\hline & delayed cystic formation & 1 & 0 & 0 & 1 & 1 & \\
\hline \multirow[t]{4}{*}{ Influence of complication on outcome } & none & 0 & 0 & 0 & 0 & 0 & 0.022 \\
\hline & mRS 1 rank down & 2 & 0 & 0 & 2 & 2 & \\
\hline & mRS 2 rank down & 1 & 0 & 1 & 0 & 1 & \\
\hline & mRS 3 rank down & 1 & 0 & 0 & 1 & 1 & \\
\hline
\end{tabular}

$3 \mathrm{~cm}$ in diameter. These results also showed a significant difference between small and larger AVMs $(\mathrm{P}<0.001)$. The size of the remaining nidus, one of the main factors defining the marginal dose of radiosurgery, was compared between the $\mathrm{S}$ and $\mathrm{N}$ groups. Remaining nidus was observed following embolization in 67 AVMs (S group: $38 / 44$ (86\%), $\mathrm{N}$ group: $28 / 29(97 \%))$. The comparison was performed between two groups that had a maximum remaining nidus diameter of more and less than $2 \mathrm{~cm}$. A smaller remaining nidus (less than $2 \mathrm{~cm}$ in maximum residual nidus diameter) was seen in 22 cases $(50 \%)$ in the $\mathrm{S}$ group but was seen in only 7 cases (24\%) in the $\mathrm{N}$ group. There were significant differences in this analysis $(\mathrm{P}=0.03)$, and the subanalysis in the 43 cases of larger AVMs excluding AVMs less than $3 \mathrm{~cm}$ in maximum diameter also demonstrated a difference $(\mathrm{P}=0.05)$.

When we performed another subanalysis with another categorization, SRS-group A +B vs. group C, there was a significant difference in the rate of successful embolization $(\mathrm{P}<0.002)$. There was no significant difference in the rate of procedure related complications (S group: 7/44 (16\%), $\mathrm{N}$ group 7/29 (24\%)) and the rate of morbidity between the two groups. Postradiosurgery complications were not encountered in the $\mathrm{S}$ group and significantly higher in the $\mathrm{N}$ group $(4 / 29(14 \%)(\mathrm{P}=0.022)$

\section{Multivariate analysis between the size and embolization specification}

We performed a selective multivariate study focusing on AVM size and embolization specification. As important factors corresponding to either the $\mathrm{S}$ or $\mathrm{N}$ group, the mRBAS, nidus type, embolization grade and residual nidus size were selected and analyzed. Of these four factors, a significant difference was obtained in the nidus type (odds ratio $0.261,95 \%$ CI: $0.073-$ $0.938, \mathrm{P}=0.04$ ) and embolization grade (odds ratio $=$ 4.397, 95\% CI 2.113-9.149, $\mathrm{P}<0.001$ ).

\section{DISCUSSION}

There have been many reports supporting the usefulness of embolization preceding surgical removal and SRS, which can make the subsequent treatment easier, safer and more successful $[1-5,16]$. By contrast, recent reports addressed the negative effect of preradiosurgical embolization. Embolization prior to SRS was associated with a lower rate of total obliteration than radiosurgery alone $[12,14]$ and had no sufficient role in reducing the recurrence correlated with deep regions [10]. The main reasons for such a result might include the followings: 1) the embolization blurs the nidus margin and causes a targeting error, 2) a part of the nidus that disappears just after the proximal feeder occlusion due to the temporary flow regression is outside of the radiosurgery target and may later recanalize due to hemodynamic remodeling [11-14, 20, 21].

For the adverse events secondary to the radiosurgery, the rate of post-radiosurgery hemorrhage is not affected by preceding embolization [21, 22]. There are conflicting reports on radiation-induced change; one shows no correlation and larger complications with preceding embolization [4, 14,23]. Additionally, it is obvious that the larger AVM may result in a lower obliteration rate for SRS. A higher tendency of the larger nidus of the virgin state was observed in the $\mathrm{N}$ group in our study. Therefore, we performed a multivariate study to clarify 
the significance of specification or quality of the embolization independent of the original AVM size. The result suggested that a successful SRS is expected to increase by more than four times for each increase in embolization grade. Therefore, the embolization grade was a strongly independent factor that influenced the success of SRS, which may suggest that a proper and meticulous embolization strategy, highly skillful microcatheterization, and best performance of injecting liquid embolic materials are essential for achieving good results. The diffuse type of AVM makes it a challenge to perform the ideal embolization. Therefore, we should preoperatively evaluate the type of nidus, and cases without the possibility of sufficient embolization should be omitted from the plan of preradiosurgical embolization. By contrast, cases with high odds of embolization that affect the positive use of embolization will contribute to and complement the desirable result of SRS.

Although we did not compare the results between two groups with and without embolization, we showed that a high quality embolization is essential to achieve ideal radiosurgery results. The embolization of nidus is particularly important for avoiding recanalization and regional vascular remodeling, as mentioned in many previous reports from the past century $[2,3,17]$. However, when treating cases with a diffuse, large AVM in which effective embolization is difficult, we should consider novel combined treatment options. Yashar et al. [24] recommends that the compartments of an embolized AVM should be contained within the radiosurgery plan. According to this concept, volumestaged radiosurgery [25-27] and preembolization radiosurgery [11] may be useful.

This study is a retrospective case cohort study of the limited institutes employing operators with a reliable and proper technique and strategy for AVM embolization. Therefore, larger prospective studies will be needed to confirm the findings.

\section{CONCLUSION}

Embolization before radiosurgery remains a controversial neoadjuvant therapy. It is clear that reducing the size and shunt flow of AVMs improves the effect of SRS. Although sufficient volume reduction should be the most important goal of embolization, false occlusion due to the temporary depression of hemodynamics may disappoint radiosurgeons. This study showed that proper embolization with a high rate of nidus penetration to avoid recanalization is important for complete, cooperative combined treatments. A proper strategy and technique is essential for promoting occlusion following SRS.

This study was supported from the grant of the 2016 Japanese Society of Neuroendovascular Therapy.

\section{Acknowledgement}

We thank Dr. Kenta Murotani (Clinical Research Center, Aichi Medical University) for statistical studies. We also thank Drs. Noriaki Matsubara and Ryo Hiramatsu (Department of Neurosurgery and Neuroendovascular Therapy, Osaka Medical College), Drs. Osamu Masuo and Kenji Kubo (Department of Neurosurgery, Wakayama Medical College), Dr. Rie Aoki (Department of Neurosurgery, Tokai University Hospital), Dr. Shuichi Tanoue (Department of Radiology, Kurume University of Medicine), Dr. Masayuki Sato (Department of Neurosurgery, Mito Medical Center), Dr. Eika Hamano (Department of Neurosurgery, National Cerebral and Cardiovascular Center) and Dr. Yosuke Tamari (Department of Neurosurgery and Endovascular Neurosurgery, Nagoya University Graduate School of Medicine) for assistance of data management.

\section{References}

1. Gobin YP, Laurent A, Merienne L, Schlienger M, Aymard A, Houdart E, et al. Treatment of brain arteriovenous malformations by embolization and radiosurgery. J Neurosurg 1996;85:19-28

2. Miyachi S, Negoro M, Okamoto T, Kobayashi T, Tanaka T, Kida $\mathrm{Y}$, et al. Embolisation of cerebral arteriovenous malformations to assure successful subsequent radiosurgery. J Clin Neurosci 2000; Suppl 1:82-85

3. Ellis JA, Lavine SD. Role of embolization for cerebral arteriovenous malformations. Methodist Debakey Cardiovasc J 2014;10: 234-239

4. Schwyzer L, Yen CP, Evans A, Zavoian S, Steiner L. Long-term results of gamma knife surgery for partially embolized arteriovenous malformations. Neurosurgery 2012;71:1139-1147

5. Blackburn SL, Ashley WW Jr, Rich KM, Simpson JR, Drzymala RE, Ray WZ, et al. Combined endovascular embolization and stereotactic radiosurgery in the treatment of large arteriovenous malformations. J Neurosurg 2011;114:1758-1767

6. Pollock BE, Flickinger JC, Lunsford LD, Maitz A, Kondziolka D. Factors associated with successful arteriovenous malformation radiosurgery. Neurosurgery 1998;42:1239-1244

7. Andrade-Souza YM, Ramani M, Scora D, Tsao MN, terBrugge K, Schwartz ML. Embolization before radiosurgery reduces the obliteration rate of arteriovenous malformations. Neurosurgery 2007;60:443-451

8. Ding D, Yen CP, Xu Z, Starke RM, Sheehan JP. Radiosurgery for primary motor and sensory cortex arteriovenous malformations: outcomes and the effect of eloquent location. Neurosurgery 2013;73:816-824 


\section{Effectivenss of Preradiosurgical Embolization of Brain AVM}

9. Starke RM, Kano H, Ding D, Lee JY, Mathieu D, Whitesell J, et al. Stereotactic radiosurgery for cerebral arteriovenous malformations: evaluation of long-term outcomes in a multicenter cohort. $J$ Neurosurg 2017;126:36-44

10. Ivanov AA, Alaraj A, Charbel FT, Aletich V, Amin-Hanjani S. Recurrence of Cerebral Arteriovenous Malformations Following Resection in Adults: Does Preoperative Embolization Increase the Risk? Neurosurgery 2016;78:562-571

11. Hodgson TJ, Kemeny AA, Gholkar A, Deasy N. Embolization of residual fistula following stereotactic radiosurgery in cerebral arteriovenous malformations. AJNR Am J Neuroradiol 2009;30: $109-110$

12. Kano H, Kondziolka D, Flickinger JC, Park KJ, Iyer A, Yang HC, et al. Stereotactic radiosurgery after embolization for arteriovenous malformations. Prog Neurol Surg 2013;27:89-96

13. Ding D, Starke RM, Kano H, Lee JY, Mathieu D, Pierce J, et al. Stereotactic radiosurgery for Spetzler-Martin Grade III arteriovenous malformations: an international multicenter study. $J$ Neurosurg 2016;15:1-13

14. Xu F, Zhong J, Ray A, Manjila S, Bambakidis NC. Stereotactic radiosurgery with and without embolization for intracranial arteriovenous malformations: a systematic review and meta-analysis. Neurosurg Focus 2014;37(3):E16. doi:10.3171/2014.6.FOCUS14178

15. Marks MP, Marcellus ML, Santarelli J, Dodd RL, Do HM, Chang SD, et al. Embolization Followed by Radiosurgery for the Treatment of Brain Arteriovenous Malformations (AVMs). World Neurosurg 2017;99:471-476

16. Izawa M, Chemov M, Hayashi M, Iseki H, Hori T, Takakura K. Combined management of intracranial arteriovenous malformations with embolization and gamma knife radiosurgery: comparative evaluation of the long-term results. Surg Neurol 2009;71:4352

17. Kondo R, Matsumoto Y, Endo H, Miyachi S, Ezura M, Sakai N. Endovascular Embolization of Cerebral Arteriovenous Malformations: Results of the Japanese Registry of Neuroendovascular Therapy (JR-NET) 1 and 2. Neurol Med Chir (Tokyo) 2014;54 Suppl 2:54-62

18. Spetzler RF, Martin NA. A proposed grading system for arteriovenous malformations. $J$ Neurosurg 1986;65:476-483
19. Wegner RE, Oysul K, Pollock BE, Sirin S, Kondziolka D, Niranjan A, et al. A modified radiosurgery-based arteriovenous malformation grading scale and its correlation with outcomes. Int J Radiat Oncol Biol Phys 2011;79:1147-1150

20. Kano H, Kondziolka D, Flickinger JC, Park KJ, Iyer A, Yang HC, et al. Stereotactic radiosurgery for arteriovenous malformations after embolization: a case-control study. J Neurosurg 2012;117: 265-275

21. Cohen-Inbar O, Starke RM, Paisan G, Kano H, Huang PP, Rodriguez-Mercado R, et al. Early versus late arteriovenous malformation responders after stereotactic radiosurgery: an international multicenter study. J Neurosurg 2016;23:1-9

22. Knippen S, Putz F, Semrau S, Lambrecht U, Knippen A, Buchfelder M, et al. Predictors for occlusion of cerebral AVMs following radiation therapy: Radiation dose and prior embolization, but not Spetzler-Martin grade. Strahlenther Onkol 2017;193; 185-191

23. Oermann EK, Ding D, Yen CP, Starke RM, Bederson JB, Kondziolka D, et al. Effect of Prior Embolization on Cerebral Arteriovenous Malformation Radiosurgery Outcomes: A CaseControl Study. Neurosurgery 2015;77:406-417

24. Yashar P, Amar AP, Giannotta SL, Yu C, Pagnini PG, Liu CY, Apuzzo ML. Cerebral arteriovenous malformations: issues of the interplay between stereotactic radiosurgery and endovascular surgical therapy. World Neurosurg 2011;75:638-647

25. Seymour ZA, Sneed PK, Gupta N, Lawton MT, Molinaro AM, Young W, et al. Volume-staged radiosurgery for large arteriovenous malformations: an evolving paradigm. J Neurosurg 2016; 124:163-174

26. Firlik AD, Levy EI, Kondziolka D, Yonas H. Staged volume radiosurgery followed by microsurgical resection: a novel treatment for giant cerebral arteriovenous malformations: technical case report. Neurosurgery 1998;43:1223-1228

27. Back AG, Vollmer D, Zeck O, Shkedy C, Shedden PM. Retrospective analysis of unstaged and staged Gamma Knife surgery with and without preceding embolization for the treatment of arteriovenous malformations. J Neurosurg 2008;109 Suppl:5764 